\title{
Território, Direitos Humanos e Educação do/no campo na Amazônia'
}

Territory, Human Rights and rural Education in the Amazon

\author{
Ricardo Gilson da Costa SILVA ${ }^{2}$ \\ Josélia Gomes NEVES 3
}

\begin{abstract}
Resumo
$\mathrm{Na}$ Amazônia brasileira as forças do agronegócio expressam objetivamente uma visão e materialização de projeto de território que afeta frontalmente à populaçáo rural e suas formas de organização social na busca de sentidos e significados aos seus modos de vida. Nesse sentido, o texto articula leitura teórica do território e experiências de campo com os processos modeladores do espaço rural. A articulação aponta como as açóes do agronegócio produzem impactos na educação do campo, que por sua vez, responde a estas investidas com mecanismos de resistência inscritas em seus modelos de escolarizaçáo que devem ser adequados aos seus contextos e interesses. Dado a evidente desproporcionalidade nestas relaçóes, a exigência dos direitos humanos constitui imperativo urgente e inadiável.
\end{abstract}

Palavras-Chave: Território. Direitos Humanos. Educação do Campo. Amazônia
Abstract

In Brazilian Amazon the agribusiness forces objectively express the vision and materialization of a territory that frontally affects rural population and its social forms of organization, signification and meanings to their lives. Therefore, the text articulates theoretical readings on territory and fieldwork experiences with the modeling processes of the rural space. This articulation points out how the actions from agribusiness agents produce impacts on rural schools education, which in turn, response to these actions with mechanisms of resistance inscribed in their educational models that must be appropriate to their contexts and interests. Given the obvious disproportionate nature of these relations, the issue requires human rights meditations as an urgent imperative.

Keywords: Territory. Human Rights. Rural School. Amazon.

1 As reflexôes neste texto resultam dos diálogos entre os grupos de pesquisa dos respectivos autores, cuja sistematização, ainda provisória, foi apresentada na Mesa de debates Educação no meio rural, políticas, espaços e temporalidades, no âmbito do SemiEdu 2017, realizado na Universidade Federal do Mato Grosso (UFMT). Essas reflexóes constituem um dos resultados do projeto de pesquisa "Agricultura, território e espaços da globalização", em desenvolvimento, pelo primeiro autor, no Programa Postdoctoral en Ciencias Humanas y Sociales da Facultad de Filosofía y Letras de la Universidad de Buenos Aires (UBA).

2 Doutor em Geografia Humana (USP), professor do Departamento de Geografia, do Programa de PósGraduação em Geografia (PPGG/UNIR) e do Programa de Pós-Graduação Interdisciplinar Profissional em Direitos Humanos e Desenvolvimento da Justiça (DHJUS/UNIR). Coordenador do Grupo de Pesquisa em Gestáo do Território e Geografia Agrária da Amazônia (GTGA) e do Laboratório de Gestáo do Território (LAGET) da Universidade Federal de Rondônia (UNIR). End.: Campus UNIR, Bloco Geografia, Sala 11, BR 364, Km 9,5, CEP, 76801-059- Porto Velho/RO. Tel.: (55) (69) 99251-7929. Email: <rgilson@unir.br>.

3 Doutora em Educação Escolar (UNESP), Professora do Departamento de Educaçāo Intercultural (DEINTER/ UNIR-Ji-Paraná) e do Programa de Pós-Graduação em Educação Escolar (MEPE/UNIR) - Mestrado Profissional da Universidade Federal de Rondônia (UNIR). Coordenadora do Grupo de Pesquisa em Educação na Amazônia (GPEA/UNIR). Coordenou a Especialização Lato Sensu da Unir do Projeto Projovem Campo Saberes da Terra (Portaria 170/GR de 16 de março de 2010. End.: Rua Gonçalves Dias, 511, CEP: 76900-692Ji-Paraná/Rondônia. Tel.: (55) (69) 99246-5611. Email: <joselia.neves@pq.cnpq.br>.

R. Educ. Públ.

Cuiabá

v. 27

n. $65 / 2$

p. $635-655$

maio/ago. 2018 


\section{Introdução}

A Amazônia brasileira vive um período de intensas transformaçóes sociais, principalmente no que se refere às dinâmicas territoriais rurais, nas quais acentuam-se a pressáo econômica do agronegócio em territórios culturais e do campesinato regional.

Trata-se de um momento histórico em que a Amazônia rural, formada pelos espaços florestal, fluvial e agrário, o que podemos qualificar de geografias da Amazônia profunda, dos espaços-tempos multidimensionais e multiescalares, vivencia os solapamentos da ação do agronegócio, associado ao capital nacional e internacional, em sua intensa busca por territórios, cujo retrato expressa a transformação da natureza em espaço do agronegócio globalizado (SILVA, 2015, 2017).

Nesse caminho, em nossa análise, relacionamos território, direitos humanos $\mathrm{e}$ educaçáo do campo, pois os consideramos como processos inter-relacionados que se sobressaem nas dinâmicas territoriais agrárias na regiâo e que cristalizam os conflitos sociais vinculados aos direitos humanos da população e comunidades rurais amazônicas.

A primeira razão deriva do reconhecimento existencial de múltiplos territórios na grande regiâo Amazônica, conformados em espaços do viver, da cultura, da produçáo e da vida social dos povos e comunidades tradicionais, assim como dos modos de vida do campesinato regional. Esses territórios estão cada vez mais pressionados pelas forças hegemônicas do agronegócio, cujo devir objetiva a produção e expansão espacial das commodities agropecuária e mineral (soja, milho, pecuária e minérios).

O segundo aspecto, como corolário, refere-se à instauração de um amplo processo de territorialização do capital que tende a produzir migraçáo e expropriação da população rural, com sérios impactos nas políticas sociais, como a educação pública do campo e suas escolas, por exemplo. Esse processo compromete a perspectiva do direito humano à educaçáo.

Nesta direção, o crescimento do agronegócio ${ }^{4}$ tem impactado na dinâmica demográfica da populaçáo rural, majoritariamente composta por camponeses

4 Vale ressaltar que este crescimento é impulsionado por investimentos significativos por parte do Estado brasileiro resultantes de articulaçóes com o legislativo federal, a bancada ruralista. Cf. O Banco do Brasil anunciou nesta terça-feira (11) R \$ 103 bilhóes para o Plano Safra 2017/2018. Desse total, R \$ 11,5 bilhóes seráo destinados para as empresas da cadeia do agronegócio e $\mathrm{R} \$ 91,5$ bilhóes seráo emprestados a produtores e cooperativas. [...] para o financiamento da agricultura familiar: R $\$ 14,6$ bilhóes serão destinados ao programa com taxa de juros que variam de 2,5\% a 5,5\% ao ano. Disponível em: <https:/g1.globo.com/economia/agronegocios/noticia/banco-dobrasil-anuncia-r-103-bilhoes-para-a-safra-2017-e-2018.ghtml>. Acesso em: 24 mar. 2018. 
e agricultores familiares, povos e comunidades tradicionais amazônicas, o que implica na migração campo-cidade (urbanização) e/ou para outros espaços rurais, ampliando a fronteira agrícola na regiáo.

O texto é de natureza reflexiva, os procedimentos metodológicos adotados consideram textos acadêmicos e vivências de campo do autor e da autora suas trajetórias acadêmicas a partir do trabalho docente, pesquisa e extensão universitária. De forma complementar adota a pesquisa documental, recurso que parte do trabalho com documentos originais, que ainda não foram analisados cientificamente (GIL, 1999), caso dos registros webgráficos - notícias, manifestos e legislaçóes publicados na internet.

As leituras bibliográficas permitiram a ampliação do eixo estruturador do artigo no intuito de articular temas e conceitos diversos para problematizar realidades complexas vivenciadas por inúmeras comunidades rurais em sua luta por território. Luta pelo direito de viver e produzir sua agri-cultura, pelo direito a ter uma escola do campo que expresse a diversidade cultural e social que permeia o cotidiano e as identidades de inúmeros grupos e comunidades rurais amazônicas.

Assim, o artigo divide-se em três partes. A primeira analisa a emergência da categoria território para o entendimento dos processos no espaço rural, indicando que a centralidade está na cristalização dos conflitos, porque expressa projetos objetivados com lógicas diferentes e antagônicas entre as classes/grupos sociais, o capital/empresas e o Estado e suas agências. A segunda problematiza os processos modeladores do território na Amazônia, focandose no agronegócio e nas lógicas de território antagônicas aos camponeses, povos e comunidades tradicionais na região. Por fim, relacionamos a análise aos nexos entre direitos humanos, educaçáo e escolas do campo, direcionada aos desafios contemporâneos diante dos processos modeladores do território na região. Dessa forma, refletimos acerca do território, direito e educação, como realidades sociais impactadas pelas dinâmicas do agronegócio e do alheamento estatal na Amazônia.

\section{Sobre o Território: alguns apontamentos teóricos}

Nesse início de século XXI as ciências sociais/humanas têm intensificado em suas pesquisas a produção sobre a categoria território, referentes às dinâmicas rurais e problemáticas socioeconômicas delineadoras de amplos aspectos da vida cotidiana e dos conflitos inerentes. Trata-se, sobre nosso entendimento, de uma categoria de análise que abrange múltiplos significados 
da vida social, dos grupos/classes sociais, das conflitualidades (FERNANDES, 2008), e que parece encontrar densidade histórica no espaço rural, visto que muitos dos estudos têm como objeto perscrutar aspectos das dinâmicas sociais territorializadas no campo 5 .

A categoria território, em síntese, expressa a espacialidade do poder. $\mathrm{Na}$ medida em que as condiçóes sociais concretas e simbólicas, materiais e imateriais, dos grupos sociais, capital, instituiçóes e Estado, em suas diversas fraçóes/agências, se interpóem como produto social histórico alicerçado em projetos coletivos (SAQUET, 2007), delineiam-se objetivos de natureza política e, portanto, espaço do conflito. Pensar em território é ter clareza que a unidade conceitual expressa uma centralidade política porque está assentada em projetos partilhados pelos grupos/agentes envolvidos (grupo social, classe social, instituiçóes e o Estado). A centralidade política é estrutural na categoria e sua operacionalização metodológica deve buscar o entendimento dos processos sociais concretos.

Pensar e analisar os processos concretos a partir do território, ao menos, implica delinear objetivamente três condiçóes: a) o território sempre é uma área (espaço físico, fixo e fluxo) apropriado e/ou dominado. $\mathrm{Na}$ dimensão da apropriação o caráter político é simbólico e cultural/imaterial, com relações sociais horizontalizadas e compartilhadas. Na perspectiva da dominaçáo a natureza política prioriza a função econômica/mercantil, com relaçôes socioeconômicas hierarquizadas e fragmentadas. No primeiro caso, o território é morada, acolhimento, trabalho, horizontalidades; no segundo, é recurso, mercadoria, capital, verticalidades (GOTTMANN, 2012; SANTOS, 1999); b) $\mathrm{O}$ território também expressa projetos que anunciam formas de usos e de construção das territorialidades, que tendem a aperfeiçoar a coerência coletiva dos sujeitos/instituiçôes com o território (área). A ideia de projeto significa que as formas de uso do território têm um sentido político, o que nos impõe pensar que não há território sem projeto político; c) $\mathrm{O}$ território é sempre gestado por sujeitos, atores, agentes, instituições. Não há território sem controle político, o que necessariamente leva-nos a pensar os sujeitos/ instituiçóes que estão em processo de gestão e controle do território, que produzem elementos sempre relacionados aos processos de territorialidades (estratégias, defesa e sentido de pertencimento). Portanto, a relação de

5 Há vários trabalhos acadêmicos que analisam os processos urbanos à luz da categoria território. Contudo, um volume expressivo da abordagem territorial se refere ao rural, ambiental, agrícola e agrário, como objeto empírico dessas análises. 
área/fluxo/fixo, projetos coletivos, controle/gestão por sujeitos/instituições encadeiam a dimensão espacial do poder, alicerce do conceito de território.

Em Raffestin (1993), a categoria território está entendida como espaço apropriado onde se projeta um trabalho, o qual pode ser designado por projeto, ideia, representação. O território é uma produção do espaço, e toda produção é sempre um processo social alicerçado a partir de relaçóes de poder. Nessa leitura, o território (conceito/processo) enseja um projeto, uma imagem do poder dos sujeitos/instituiçóes que lhes dão existência. Deduz-se que o território pode ser espaço de poder tanto do Estado e suas agências quanto dos movimentos sociais, das empresas nacional e internacional, de um conjunto de sujeitos/ instituiçóes que de algum modo manifestam seus projetos e frequentemente os materializam sobre a instituição do conflito.

Haesbaert (2014) analisa essa dupla conotação - material e simbólica - do território, argumentando que essa categoria pode ser utilizada na análise em três aspectos: como categoria teórica, como categoria da prática e como categoria normativa. No primeiro caso, temos as análises acadêmicas referentes aos objetos de pesquisas; no segundo, o território emerge como referência da ação política dos movimentos sociais e do capital; por fim, o território como prática do Estado e suas agências, isoladas ou associadas às reivindicaçóes e pautas dos demais sujeitos/instituiçóes. Fernandes (2008) ressalta o princípio da totalidade, multidimensionalidade e da multiescalaridade para a categoria território. Para o autor, a essencialidade da categoria território está na capacidade de conceber e analisar as relaçóes de poder a partir dos princípios que norteiam os aspectos mais locais e globais no processo de apropriação e dominação dos espaços, ressaltando que a conflitualidade é condição de formação de territórios. Explica que como espaço de governança (políticas públicas), propriedades privadas (agronegócio, terra de negócio) ou como propriedades coletivas (territoriais culturais, assentamentos rurais, terra de trabalho), o território apresenta totalidade e projetos distintos (SAQUET, 2007).

Com o fenômeno da globalização avançando em todos os continentes, o território expressa a totalidade do mundo, sendo o "[...] lugar em que desembocam todas as açóes, todas as paixões, todos os poderes, todas as forças, todas as fraquezas, isto é, onde a história do homem plenamente se realiza a partir das manifestações da sua existência" (SANTOS, 1999, p. 7). A condição de existência é o pertencimento coletivo do espaço apropriado, cristalizado em projetos que criam unidade - diferente de unicidade - aos sujeitos envolvidos. Aqui vê-se a dialética do território, porque ele assume as dimensóes da vida social e dos conflitos em seus delineamentos. 


\section{Principais dinâmicas territoriais agrárias na Amazônia}

Ao relacionarmos perspectivas analíticas de território com os processos dinamizadores do espaço rural amazônico, notadamente se verifica que as açóes e projetos encaminhados pelas forças hegemônicas do agronegócio alimentam a modernização tecnológica do rural amazônico, com graves consequências espaciais, do ponto vista da funçáo econômica da regiáo, com efeitos devastadores na natureza e nos territórios do campesinato, dos povos e comunidades tradicionais amazônicas.

Por agronegócio - lato sensu - entende-se a modernização do latifúndio vinculado à produção de commodities agrícolas. As perspectivas liberal e conservadora tratam o agronegócio como um conceito normativo e sistêmico, que articula a produção agrícola à sua industrialização e comércio, ou seja, busca à superação da análise setorial dos processos econômicos, potencializando no campo político, econômico, social e ideológico esse conceito. Os produtos agropecuários e minerais qualificados como commodities objetivam o mercado externo, a exportaçáo, ou seja, trata-se de uma atividade produtiva que aliena o território, submetendo-os aos fluxos global da economia (SANTOS, 1999).

Nesse aspecto, para a análise, nos parece relevante indicar duas tendências do agronegócio que se adensam na Amazônia. Primeiro, refere-se ao controle de grandes áreas agrícolas e estoque de terras para a sua expansão, fazendo da regiáo uma reserva espacial global do agronegócio. Em outras palavras, para o agronegócio, não basta o investimento em tecnologia e o aumento da produtividade dos fatores de produção, argumentos amplamente divulgados em suas propagandas e marketings, sendo necessário e estratégico o controle de terras e de territórios (SILVA, 2015, 2017).

A segunda característica se refere à forte concentração econômica dos agentes hegemônicos, notadamente as grandes empresas multinacionais, que controlam os mecanismos dos processos produtivos e seus fluxos, da produçáo ao mercado externo, o que permite a formação de grandes oligopólios (LEITE; MEDEIROS, 2012). Assume-se um tácito projeto de território (latifúndio, grandes produtores e empresas nacional/multinacional) que não comporta as populaçôes rurais, considerando que essas vivenciam o que podemos chamar território e territorialidades coletivas e compartidas, não mediadas e alimentadas por lógicas globais e estranhas ao convívio social historicamente territorializados na relação grupo social, natureza, cultura e lugar.

A perspectiva crítica entende o agronegócio como um projeto de poder, que reúne tanto os aspectos produtivos e tecnológicos, quanto uma clara dimensáo 
ideológica da natureza, da sociedade e do território, no sentido de aprofundar a mercantilização e a dominação dos espaços, implicando no ataque aos territórios coletivos, territórios culturais. Essa perspectiva de dominação está muito presente na propaganda promovida pela Rede Globo de televisão, dado que a narrativa do rural como Agro é tech, agro é pop, o agro é tudo, encaminha uma visão totalitária dos processos socioeconômicos, expressa na ideologia de que o único modelo produtivo para o espaço rural no Brasil seria o pautado pelas forças hegemônicas do agronegócio, inclusive com um esforço de inserir a agricultura familiar nesse processo. Tratam como obsoletas e atrasadas todas e quaisquer formas de uso do território que não estejam assentadas na racionalidade econômica da produção de commodities. Nessa ótica, não há direitos e territórios para os indígenas, ribeirinhos, assentados, seringueiros, quilombolas, camponeses, instaurando o conflito que assume múltiplas dimensōes (social, simbólico, econômico e territorial).

A propaganda do governo e dos grandes meios de comunicação exalta o crescimento econômico e espacial do agronegócio, mas frequentemente omite as consequências desse processo, concretamente expresso nos impactos ambientais, na destruição dos territórios do campesinato, dos povos indígenas e das comunidades tradicionais amazônicas, como atualmente se verifica em todos os Estados da Amazônia brasileira. Em casos concretos, o agronegócio encaminha dois processos modeladores que atingem as condiçóes sociais elementares das populaçóes e comunidades rurais, incidindo no acesso e permanência dos estudantes nas escolas rurais na Amazônia.

Primeiro, destacamos a formação do espaço das monoculturas. A produção de commodities vincula-se ao mercado externo e introduz no meio social o processo de alienação do território e do espaço rural, tanto nas dinâmicas produtivas, quanto nas condiçóes territorial e simbólica. As atividades agrícolas e os processos socioeconômicos que elas ensejam respondem aos fluxos e dinâmicas exógenas, o que frequentemente implica na desestabilização e no mecanismo de desterritorialização de comunidades e povoados rurais, considerando que para o crescimento econômico a estratégia ou a condição do agronegócio implica na ampliação e concentração de extensas áreas agrícolas, produzindo mais latifúndios (SILVA; CONCEIÇÃO, 2017).

Soja, milho, pecuária de corte, cana-de-açúcar, minério de ferro e bauxita compóem o pacote das principais commodities (agropecuárias e minerais) produzidas na Amazônia. O conjunto da produção arquiteta a paisagem da monocultura, dos latifúndios e esvaziamento populacional do campo. A espacialidade do agronegócio é limitadora da diversidade sociocultural. Consequentemente, aprofunda-se a pressão sobre os territórios coletivos (assentamentos rurais), territórios culturais dos povos e comunidades 
tradicionais amazônicas (seringueiros, indígenas, quilombolas, extrativistas, pescadores artesanais e outros) e unidades de conservaçáo, resultando em crescentes conflitos agrários e territoriais, como anualmente denunciam a Comissão Pastoral da Terra e o Conselho Indigenista Missionário em seus relatórios sobre conflitos agrários e contra os povos indígenas no Brasil (CPT, 2016; CIMI, 2016).

O agronegócio expande, para quase todas as sub-regióes da Amazônia, suas estratégias de inserção das commodities como mecanismos de modernização agrícola e, contraditoriamente, de exclusão territorial. Onde avançam as monoculturas frequentemente tem-se como corolário o aumento do preço da terra e consequente corrida pela terra, migração e concentração fundiária. Assim, os territórios dos camponeses e as formas coletivas de uso da terra e de produção familiar vivem permanentemente restringidos pela força econômica do agronegócio globalizado (SILVA; CONCEIÇÃO, 2017).

Outro processo relevante engendrado pelo agronegócio refere-se ao que qualificamos como imperativo territorial (SILVA, 2017). A análise das commodities náo deve se restringir aos aspectos produtivos e tecnológicos, características amplamente divulgadas pelo marketing e propaganda das instituiçóes do agronegócio. É necessário ampliar a leitura e compreender as conexóes entre as lógicas das commodities com o espaço em transformação, que constitui o território do agronegócio.

Somado à estrutural concentração fundiária, o agronegócio também impóe o controle de terras. Portanto, obliterar o acesso à terra comparece como condição de controle/domínio social sobre a população rural e comunidades rurais. A literatura especializada indica que para a produção e a produtividade da agropecuária o fator terra já não apresenta a mesma intensidade inerente aos processos produtivos pretéritos, visto que a tecnologia favoreceu sobremaneira a produtividade do setor agrícola (BUAINAIN, 2014). Todavia, o fator terra, o controle da terra e a formação de latifúndios continuam centrais nas dinâmicas territoriais do agronegócio, o que ainda demonstra a dimensão política da grande propriedade na formação socioespacial do Brasil. Qual a lógica desse processo no tempo presente?

Da ótica da economia política, a terra serve como mecanismo de acumulação e de reprodução de fraçóes do capital. Parte das empresas investe na compra de terras como reserva de capital, como garantias para acessar os financiamentos e, historicamente, como especulação fundiária. $\mathrm{O}$ agronegócio substantiva esse processo quando contemporaneamente estimula uma nova corrida pela terra na Amazônia, agora qualificando a regiáo como fronteira agrícola globalizada (SILVA, 2015, 2017). Os agentes dessa busca por novas terras são empresas 
nacionais, multinacionais, proprietários que migraram das regióes sul e sudeste em direção à Amazônia e, mais recentemente, para o sul do Maranháo, leste do Tocantins, sul do Piauí e oeste da Bahia, região conhecida como MATOPIBA.

Intensificam-se os elementos multidimensionais e multiescalares dos processos produtivos e das disputas territoriais e agrárias na região, ou seja, produz-se uma geografia onde os camponeses e os povos e comunidades tradicionais amazônicas encontram-se ameaçados em seus territórios e propriedades familiares, visto que a corrida pela terra fez aumentar o preço da terra, com consequente expropriação, coerção territorial e conflitos agrários na região (SILVA, 2017). Traduz-se em poderoso componente político das forças do agronegócio limitar a disponibilidade de terras às formas coletivas, familiares e culturais de produção agropecuária, cujos territórios e territorialidades preenchem a Amazônia de riqueza social e cultural inestimável.

Mas o imperativo territorial do agronegócio não se contenta em limitar e bloquear o acesso à terra aos camponeses, comunidades e povos étnicos nos espaços rural, agrário, fluvial. Contemporaneamente, o fluxo da especulação fundiária e expropriação da natureza direcionam-se às terras públicas, áreas indígenas, áreas quilombolas, unidades de conservação, ao que chamamos de áreas protegidas. Desse modo, a dominação do território efetiva-se pelos mecanismos das invasóes e grilagens de terras públicas, comércio ilegal de terras e uma poderosa propaganda, cuja narrativa sustenta que há excesso de áreas protegida no Brasil, e que tal condição estaria obstruindo o crescimento econômico do país. Na Amazônia brasileira o resultado está no aumento dos conflitos agrários e na sua letalidade (assassinatos), na pressão econômica do agronegócio que gera coerção territorial na regiáo, vitimando o campesinato e suas lideranças sociais, intelectuais orgânicos dos movimentos socioterritoriais (CPT, 2016).

Em síntese, o controle de terras pelo agronegócio implica em bloquear a reforma agrária, uma necessidade histórica dos camponeses brasileiro. $\mathrm{O}$ controle do território indica que tanto as terras privadas quanto as terras públicas passam a ser disputadas e gestadas pelos mecanismos coercitivos do agronegócio.

$\mathrm{Na}$ leitura das forças do agronegócio, não há direitos, territórios e esperança para os povos e comunidades tradicionais amazônicas. $\mathrm{O}$ agronegócio impóe um projeto único de território, um simbolismo de mercado, destituído de diversidade social. Onde cresce o agronegócio a diversidade social tende a diminuir, porque expropria a população do campo e ameaça as comunidades rurais. Trata-se de uma perspectiva, ideia e projeto de território absoluto, negadora de territórios plurais. E neste contexto, políticas sociais como a educação são duramente afetadas e os direitos humanos violados. 
No entanto, mesmo diante de um quadro tão assimétrico, há produção de resistências e mobilizaçóes encaminhadas pelas comunidades rurais e movimentos sociais do campo por meio de epistemologias próprias inspiradas e mobilizadas nas aprendizagens experienciais, sugerindo caminhos alternativos ao imperativo da racionalidade técnica da sociedade capitalista. Como tem demonstrado diversas experiências na Amazônia, como a Marcha das Margaridas, que em 2007 evidenciou o lema: Contra a fome, a pobreza e a violência sexista, realizada periodicamente em Brasília (SILVA, 2008). A luta pela educação do/no campo, neste sentido é uma das lutas também epistêmicas e existencial, porque reconhece a diferença como direito dos povos e comunidades que se negam a serem pautados e visibilizados pelas métricas e cânones da racionalidade do capital, compreensão que mobiliza a elaboração de suas próprias respostas (SANTOS; ARAÚJO; BAUMGARTEN, 2016).

\title{
Educação do campo na perspectiva dos Direitos Humanos: aproximações necessárias
}

\begin{abstract}
A educação do campo é vista como uma luta por direitos dos que trabalham no campo. Assim, o surgimento desse segmento específico da educação destinada aos camponeses está atrelada a uma educação diferenciada e alternativa que se assuma enquanto processo de formação humana. (NASCIMENTO, 2009, p. 169).
\end{abstract}

A fronteira entre os espaços urbanos e não urbanos tem produzido um conjunto de representaçóes hierárquicas de caráter assimétrico com evidentes prejuízos para as populaçóes que residem no campo. $\mathrm{Na}$ atualidade, mesmo reconhecendo as transformaçóes agrárias e agrícolas no Brasil, ainda persistem concepçóes estereotipadas de que quem mora no espaço não urbano é percebido como atrasado, sem conhecimento, identidades representadas em imagens como Jeca Tatu, de Monteiro Lobato, ou nos quadrinhos de Mauricio de Souza, por meio do personagem Chico Bento.

Nesse sentido, a educação pensada inicialmente para esses espaços estabelecia correspondência com tais percepçóes na medida em que o propósito era de salválos da ignorância (ARROYO; FERNANDES, 1999). A educação propiciada pelo Estado brasileiro aos sujeitos do campo evidenciava: "[...] de um lado o descaso dos dirigentes com a educação do campo e de outro, os resquícios de matrizes culturais vinculadas a uma economia agrária apoiada no latifúndio e no trabalho escravo" (BRASIL, 2001, p. 3). 
Assim, nada mais era que uma adaptação apressada dos modelos educacionais urbanos e suas características (MOLINA, FREITAS, 2011), com a vitrine dos valores consumistas desencadeados pela sociedade industrial com a propaganda de que a cidade era melhor para viver do que o campo, desconsiderando que uma educação de sentidos é aquela que leva em conta: "[...] os aspectos da diversidade, da situação histórica particular de cada comunidade, os recursos disponíveis, as expectativas, os anseios dos que vivem no campo" (SILVA JÚNIOR; BORGES NETTO, 2011, p. 53).

Embora houvesse vastos reconhecimentos das características agrárias do Brasil, apenas a Constituição Federal de 1988 estabeleceu o direito à educação para todos e a obrigaçáo do Estado quanto a sua implantação e manutenção. Após oito anos, a Lei de Diretrizes e Bases da Educação Nacional, no 9.304/1996, instituiu as normas de funcionamento para a educação do campo, considerando:

[...] às peculiaridades da vida rural e de cada regiáo [...] conteúdos curriculares e metodologias apropriadas às reais necessidades e interesses dos alunos da zona rural; organização escolar própria, incluindo a adequação do calendário escolar às fases do ciclo agrícola e às condiçóes climáticas; adequação à natureza do trabalho na zona rural. (BRASIL, 1996, p. 1, grifo nosso).

Ainda que esses princípios representem um marco importante na legislação educacional, era preciso elaborar normas mais específicas. Desse modo, a inserção da educação na pauta de luta dos movimentos sociais do campo a partir de 1997 problematizou o modelo existente no I Encontro Nacional de Educadores e Educadoras da Reforma Agrária (I ENERA), promovido pelo Movimento dos Trabalhadores Rurais Sem-Terra (MST), em Brasília (ARROYO, FERNANDES, 1999). Nessa ocasião, foi feito um balanço da educação do campo, cujos resultados apontaram para a necessidade de elaboração de uma proposição crítica na perspectiva camponesa:

[...] se constituiu num espaço de apresentaçáo pública das experiências formativas e educativas do MST, e também um espaço de reivindicação e luta pelo acesso ao direito de estudar no campo em condiçôes dignas e com uma proposta educacional que considerasse a especificidade, diversidade e a perspectiva de projeto defendido por estes sujeitos. (SILVA, 2015). ${ }^{6}$

6 Silva (2015). Disponível em: <http://www.mst.org.br/2015/07/15/enera-tem-o-desafio-de-criar-umnovo-espaco-de-articulacao-entre-os-trabalhadores-da-educacao.html>. Acesso em: 15 mar. 2018. 
Essa proposição crítica forneceu os elementos necessários para a escrita das Diretrizes Operacionais para a Educação Básica nas Escolas do Campo, observando esse espaço em visão ampla: "O campo, nesse sentido, mais do que um perímetro não-urbano, é um campo de possibilidades que dinamizam a ligação dos seres humanos com a própria produção das condições da existência social e com as realizaçóes de sociedade humana" (BRASIL, 2001, p. 1). Nessa direção, o atual desenho da educaçáo do campo representa o resultado do trabalho protagonizado pelos principais interessados, no âmbito dos direitos humanos, expressa por um conjunto de práticas e lutas ancoradas em concepçóes de aprendizagens próprias da população do campo, confirmando com Paulo Freire que:

A educação para os direitos humanos, na perspectiva da justiça, é exatamente aquela educação que desperta os dominados para a necessidade da briga, da organizaçáo, da mobilização crítica, justa, democrática, séria, rigorosa, disciplinada, sem manipulaçôes, com vistas à reinvençáo do mundo, à reinvençáo do poder. [...] essa educação tem que ver com uma compreensão diferente do desenvolvimento, que implica uma participação, cada vez maior, crescente, crítica, afetiva, dos grupos populares. (FREIRE, 2001, p. 99).

Desse modo é que analisamos a educação do campo e sua vinculação aos direitos humanos, na medida em que é percebida como um modelo formativo que reivindica direitos comumente violados, não alcançados pela legislação no que se refere às desigualdades ainda existentes quanto à sua plena efetivação (LOCKS; GRAUPE; PEREIRA, 2015).

De acordo com o Plano Nacional de Educação em Direitos Humanos (PNEDH), a educação constitui uma possibilidade de fortalecimento da democracia e com essa compreensão, busca "[...] contribuir para dar sustentação às ações de promoção, proteção e defesa dos direitos humanos, e de reparação das violações" (BRASIL, 2007, p. 26). E no que se refere a educação em espaços não urbanos se compromete a: "Apoiar as políticas públicas dirigidas às escolas de educação indígena, quilombolas e de educação no campo" (BRASIL, 2007, p. 26) ${ }^{7}$. Embora o verbo apoiar possa aparentemente sugerir insuficiência, é importante pela inserçáo e visibilidade dessas modalidades diferenciadas.

7 Vale complementar que aconteceu em 15/09/2005 em Porto Velho- RO o Encontro Estadual de Educação em Direitos Humanos realizado pelo Comitê Estadual de Educaçáo em Direitos Humanos de Rondônia, ocasião em que a $2^{\mathrm{a}}$ autora participou como representante da Universidade Federal de Rondônia. A açáo referente à inserção da população não urbana - população do campo, povos indígenas, extrativistas e ribeirinhos foi parcialmente contemplada no Plano Nacional de Educação em Direitos Humanos. (BRASIL, 2007). 
Assim, a educação do campo em Rondônia, na perspectiva dos direitos humanos, vem problematizando algumas questóes que evidenciam descumprimento explícito à política de direitos fundamentais e à legislação estabelecida, como o fechamento de escolas, por meio do reordenamento das chamadas escolas-polo (SUAVE, 2017).

Sobre o assunto, o Movimento de Pequenos Agricultores (MPA) denuncia que no município de Colorado do Oeste, sul de Rondônia, no período de 1990 a 2000, existiam 85 escolas do campo. No entanto, com a implantação da polarização, sem diálogo nenhum com as comunidades, restaram apenas cinco escolas. Na perspectiva da comunidade:

Este processo perverso provocou vários transtornos para o Campesinato, como por exemplo, esvaziamento do campo e sofrimento dos estudantes que percorrem de longas distâncias, trechos de estradas péssimas e transportes inadequados para levar os mesmo até as escolas. Como se todos estes mal causados contra os camponeses não bastassem, a atual administração decidiu sem o conhecimento dos pais e comunidade escolar, transferir os estudantes de $6^{\circ}$ ao $9^{\circ}$ para o Estado por meio de um termo técnico de cooperação (Reordenamento) justificando-se em leis e decretos federais. Conhecedores da política de extinção das escolas, que sempre começa de forma camuflada, com muitas promessa enganosas, como aconteceu no passado, dessa vez foi diferente, os pais se revoltaram, pois sabiam que isso acontecendo estes educandos seriam transferidos para cidade em um curto espaço de tempo, uma vez que no campo de Colorado não tem Escolas Estaduais somente as Municipais e construir Escolas Estaduais no campo não faz parte da política do Governo de Rondônia, uma vez que o mesmo vem implantando o ensino a distância por meio da Mediação Tecnológica $[\ldots]^{8}$

É possível observar que houve uma decisão arbitrária por parte dos sistemas estadual e municipal, sem considerar os interesses campesinos. A mobilização foi o caminho encontrado para problematizar a prefeitura por meio de várias açôes: envio

8 CAMPONESES garantem conquista na Educação do Campo em Colorado do Oeste - RO. Disponível em: <http://mpabrasil.org.br/camponeses-garantem-conquista-na-educacao-do-campo-em-colorado-dooeste-ro/>. Acesso em: 18 dez. 2017. 
de documentos amparados pela legislação da educação e da educação do campo, divulgação nas mídias locais e redes sociais, explicitando o ocorrido, e denúncia formal ao Ministério Público Estadual, reivindicando a permanência dos estudantes do sexto ao nono ano na rede municipal. O desfecho final desse tensionamento ocorreu em um encontro que envolveu a comunidade camponesa e o executivo municipal, em uma reuniáo realizada numa escola do município de Colorado do Oeste, em outubro de 2017, com a presença de cerca de 100 pessoas, que pressionavam o prefeito para que revogasse o Termo de Cooperação assinado com o Estado:

Após o prefeito ouvir os pais [...], José Ribamar, que já tinha dito que náo revogaria o termo, sentindo pressionado resolve revogar e se dispôs a discutir com a comunidade melhorias que a comunidade julgar necessária nas escolas rurais, como também, assumiu o compromisso de junto com a militância e lideranças de escolas, pais e professores, reconstruir a pedagogia das cinco escolas do campo existente no município, bem como reconstruir o currículo numa perspectiva camponesa e no projeto de afirmaçáo da identidade de quem vive no campo. Pais e comunidades presentes comemoram a conquista que parecia impossível, [...]. Reconhecendo que a escola náo é apenas um lugar onde seus filhos estudam, ela faz parte da história da comunidade, é o lugar onde o povo se encontra, reúnem as diversidades culturais, religiosas, politicas e sociais pra tomar as decisóes importantes e especiais da vida da comunidade.

Essa situação que ocorreu recentemente em Rondônia permite a interpretação que medidas como essas, de reordenamento escolar, acarretam alteraçóes no modo de vida das pessoas e, por sua vez, no território, na medida em que resulta no esvaziamento da população do campo. Inegavelmente, esses impactos têm acontecido em todo o país, pois estudos confirmam que: "Muitas escolas públicas rurais isoladas foram fechadas sob a alegação de que o número de alunos não era suficiente para a manutenção das turmas e classes escolares" (SOUZA; MARCOCCIA, 2011, p. 193).

O estudo de Biazatti (2012), sustenta que na perspectiva dos gestores públicos trata-se de uma medida de otimizaçáo de recursos materiais e humanos. No que diz respeito à otimizaçáo de recursos materiais sustentam que, com essa

9 Camponeses garantem conquista na Educação do Campo em Colorado do Oeste - RO. Disponível em: <http://mpabrasil.org.br/camponeses-garantem-conquista-na-educacao-do-campo-em-colorado-dooeste-ro/>. Acesso em: 18 dez. 2017. 
propositura, a escola-polo acaba com o isolamento e proporciona, além das salas de aula, espaços específicos para biblioteca, audiovisuais, sala de reuniáo, auditório, quadra de esportes, por exemplo.

Embora a política de agrupar escolas no campo apresente aspectos positivos - como os de superar o isolamento e o abandono ao qual estiveram condenadas e, ainda, alocar apoio administrativo para melhorar as condiçōes de trabalho ao professor - suscita problemas decorrentes do fechamento de escolas, principalmente para as famílias que residem no meio rural. (FARIA, 2007, p. 7).

Sobre os recursos humanos os gestores entendem que essa medida permite a presença de um coletivo docente e gestor composto por professores e professoras por turma, rompendo, assim, a clássica imagem das escolas rurais multisseriadas ou unidocentes, coordenadas por um único professor (a). Assim, conta com profissionais na direção, na coordenação pedagógica e equipe de limpeza (BIAZATTI, 2012).

De acordo com esta autora, esse modelo tem sido profundamente rejeitado pelas comunidades do campo uma vez que provoca o desenraizamento e longos deslocamentos dos estudantes das suas localidades, o que exigiu uma política de transporte. Mas ainda há críticas nesse sentido, evidenciadas na manchete: "Direito negado: fechamento de escolas rurais obriga crianças a passar mais tempo na estrada que em aula." 10

Estudos apontam que, entre 2002 e 2009 , mais de 24 mil escolas do campo foram fechadas no Brasil. Os dados do Censo Escolar do Instituto Nacional de Estudos e Pesquisas Educacionais (Inep), do Ministério da Educação, apontam que, no meio rural, existiam 107.432 escolas em 2002. Já em 2009, o número de estabelecimentos de ensino reduziu para $83.036^{11}$, na maioria das vezes sem discussão alguma com a comunidade interessada (SUAVE, 2017).

De posse desses alarmantes dados e como conhecedores da realidade do campo, o Movimento Sem Terra (MST), apoiado por docentes, intelectuais e outras entidades, lançou em outubro de 2011 o manifesto Fechar escolas é

10 Disponível em: <http://www.redebrasilatual.com.br/educacao/2017/03/fechamento-de-escolar-ruraisobriga-criancas-a-passar-mais-tempo-na-estrada-do-que-em-sala-de-aula>. Acesso: 18 dez. 2017.

11 EDUCADORES lançam manifesto contra o fechamento de escolas no meio rural. Disponível em: <https://www.revistaforum.com.br/2011/10/17/educadores-lancam-manifesto-contra-o-fechamento-deescolas-no-meio-rural/>. Acesso: $18 \mathrm{dez} .2017$. 
crime, que denunciava o fechamento das escolas do campo e exigia a elaboração de políticas públicas mais consistentes e democráticas para essa modalidade educativa. Três anos depois foi sancionada pela presidenta Dilma Rouseff a Lei $\mathrm{n}^{\circ} 12.960$, de 27 de março de 2014, uma emenda no artigo 28 da LDB no 9.394/1996, estabelecendo:

O fechamento de escolas do campo, indígenas e quilombolas será precedido de manifestação do órgáo normativo do respectivo sistema de ensino, que considerará a justificativa apresentada pela Secretaria de Educação, a análise do diagnóstico do impacto da ação e a manifestação da comunidade escolar. (BRASIL, 2014, p. 1).

Certamente, a instalação de uma escola no campo significa o cumprimento da pactuação social na ótica do direito e a efetivação das obrigaçôes do poder público no espaço onde as populaçóes campesinas residem e constroem suas existências. A publicação dessa Lei normatiza a política de fechamento de escolas do campo no Brasil; assim, só pode ocorrer fechamento de instituiçóes escolares após parecer do Conselho Municipal ou Estadual de Educaçáo, com o consentimento da comunidade.

Portanto, a trajetória da educaçáo do campo evidencia que as propostas educacionais governamentais para o campo, em várias situaçôes, representam graves violações aos direitos humanos: a ausência de diálogo, medidas autoritárias e burocratizadas (de cima para baixo), argumentos que levam em conta mais os aspectos orçamentários que as pessoas, como o desenraizamento de suas comunidades, o risco de acidentes, o cansaço físico e mental imposto por essa rotina nas precárias estradas de chão. Nunca é demais relembrar:

[...], o clamor dos camponeses, que em primeiro lugar deve vir as pessoas e náo a produção para o agronegócio, que a Educaçáo do Campo nasceu tomando posiçáo no confronto de projetos de campo: contra a lógica do campo como lugar de negócio, que expulsa as famílias, que não precisa de educação nem de escola. (CALDART, 2010, p. 20).

Assim, os aparentes desencontros entre a gestáo do sistema de educação, por meio das açóes das secretarias municipais ou estadual e as populaçóes do campo, parecem explicitar que há divergências ou alheamentos relacionados à interpretação do direito humano à educação para as pessoas que vivem no e do campo.

E possível inferir que a ação estatal no direcionamento de políticas públicas, aliada à expansão do agronegócio, tem produzido alteraçôes demográficas de 
diminuição da população do campo, formada comumente por camponeses (as) e agricultores (as) familiares, talvez uma reedição dos elementos explicativos do êxodo rural, resultante ora de expulsão, ora de atração: "A expulsão, [...] é decorrente da modernização do campo, que privilegiou os grandes latifundiários, não incluindo o agricultor familiar. E a atração que as cidades exerceram [...] que náo correspondia com a realidade dos trabalhadores do campo" (SILVA JÚNIOR; BORGES NETTO, 2011, p. 48). Diante desse quadro, cabe aos camponeses e camponesas o movimento permanente de luta pela construção de um território e uma escola com significado e sentido para sua gente.

\section{Consideraç̃̃es finais}

O que poderíamos chamar de fenômeno de fechamento das escolas rurais está associado ao modelo econômico e territorial nos espaços rurais, hegemonicamente pautado na expansão da grande propriedade (latifúndio), agora atualizado pelo agronegócio.

Esse processo ganha relevância particular na Amazônia brasileira por ser essa regiáo a que apresenta maior percentual de população rural no país, formada por inúmeras comunidades rurais, organizadas em territórios e assentadas em territorialidades, saberes e experiências/vivências com a natureza.

Como analisamos, a expansão do agronegócio resulta em concretizar um projeto de território - espacialidade do poder - que tende a submeter os lugares, comunidades rurais e povos étnicos aos processos coercitivos da racionalidade do capital globalizado. Para as populaçóes rurais, em seus múltiplos territórios, incide na disputa por um modelo de educação do campo que valorize seus elementos produtivos e simbólicos formados no processo histórico de lutas sociais, derrotas e conquistas.

As aceleradas dinâmicas territoriais na Amazônia, no qual a construção de poderosas infraestruturas portuárias, hidrovias, rodovias e hidrelétricas, somada à corrida pela terra estimulada pelo agronegócio, sinalizam que os conflitos assumem outras dimensóes, cujas escalas geográficas objetivamente relacionam o local e o global.

No âmbito desse debate e disputas articulam-se conceitos e concepçóes como processos sociais importantes na defesa do direito à educaçáo, à escola, à terra e ao território. Dessa forma, refletimos acerca do território, direito e educação, como realidades sociais impactadas pelas dinâmicas do agronegócio na Amazônia, cuja ação do Estado frequentemente penaliza as comunidades rurais e o que podemos qualificar como a diversidade social dos territórios amazônicos. 


\section{Referências}

ARROYO, M.; FERNANDES, B. M. A educaçáo básica e o movimento social no campo. Brasília, DF: Articulação nacional por uma educação básica do campo, 1999. (Coleção Por uma educação básica no campo. v. 2.)

BIAZATTI, S. C. Migraçóes rurais: um estudo do sentido das migraçóes no campo e suas implicaçóes nas comunidades atendidas pela escola Irineu Antonio Dresh. Trabalho de Conclusão de Curso (Graduação em Pedagogia) - Universidade Federal de Rondônia, Porto Velho, 2012. 35 p.

BUAINAIN, A. M. et. al. (Ed.). O mundo rural no Brasil do século 21: a formação de um novo padrão agrário e agrícola. Brasília, DF: Embrapa, 2014.

BRASIL. Constituição (1988). Constituição da República Federativa do Brasil: texto constitucional promulgado em 5 de outubro de 1988. Brasília, DF: Senado Federal, Subsecretaria de Ediçóes Técnicas, 1988.

BRASIL. Ministério de Educação e Cultura. LDB - Lei n. 9394/96, de 20 de dezembro de 1996. Estabelece as diretrizes e bases da Educação Nacional. Brasília, DF: MEC, 1996.

BRASIL. Ministério da Educação. Conselho Nacional de Educação. Diretrizes Operacionais para a Educaçáo Básica nas Escolas do Campo. Brasília, DF, 2001.

BRASIL. Comitê Nacional de Educação em Direitos Humanos. Plano Nacional de Educaçáo em Direitos Humanos. Brasília, DF: Secretaria Especial dos Direitos Humanos, Ministério da Educação, Ministério da Justiça, UNESCO, 2007.

BRASIL. Presidência da República. Lei n. 12.960, de 27 de março de 2014. Dispóe sobre o sistema de ensino para o fechamento de escolas do campo, indígenas e quilombolas. Diário Oficial da República Federativa do Brasil. Poder Executivo, Brasília, DF, 28 mar. 2014, Seção 1.

CALDART, R. S. Concepção de Educação do Campo. In: Centro Vianei de Educaçáo Popular. Projeto Educação do Campo: Novas Práticas. Lages: Editora Inês, 2010.

CIMI - CONSELHO INDIGENISTA MISSIONÁRIO. Relatório Violência contra os povos indígenas no Brasil - Dados de 2016. Brasília, DF: CNBB, 2016. Disponível em: <https://www.cimi.org.br/pub/relatorio/Relatorioviolencia-contra-povos-indigenas_2016-Cimi.pdf>. Acesso em: 14 dez. 2017. 
CPT - COMISSÃO PASTORAL DA TERRA. Caderno Conflitos no Campo - Brasil 2016. Goiânia: CPT, 2016. Disponível em: <https://www.cptnacional. org.br/publicacoes-2/destaque/3727-conflitos-no-campo-brasil-2016>. Acesso em: 14 dez. 2017.

FARIA, R. Educação e municipalidade no Brasil: impactos e contradiçóes das políticas públicas federais nos sistemas públicos municipais de ensino: o caso do município de Trajano de Moraes. In: SIMPÓSIO BRASILEIRO DE POLÍTICA E ADMINISTRAÇÃO DA EDUCAÇÃO, 23.; CONGRESSO LUSO-BRASILEIRO DE POLÍTICA E ADMINISTRAÇÃO DA EDUCAÇÃO, 5.; COLÓQUIO IBERO-AMERICANO DE POLÍTICA E ADMINISTRAÇÃO, 1., 2007, Porto Alegre. Cadernos ANPAE n. 4... Porto Alegre: 11-14 nov. 2007. Disponível em: <www. anpae.org.br/congressos_antigos/simposio2007/382.pdf>. Acesso em: $14 \mathrm{dez} .2017$.

FERNANDES, B. M. Entrando nos territórios do território. In: PAULINO, E. T.; FABRINI, J. E. (Org.). Campesinato e territórios em disputa. São Paulo: Expressão Popular, 2008. p. 273-301.

FREIRE, P. Direitos humanos e educação libertadora. In: FREIRE, Ana Maria Araújo (Org.). Pedagogia dos sonhos possíveis. São Paulo: UNESP, 2001.

GIL, A. C. Métodos e Técnicas de Pesquisa Social. 5. ed. São Paulo: Editora Atlas. 1999.

GOTTMANN, J. A evolução do conceito de território. Boletim Campineiro de Geografia, v. 2, n. 3, p. 523-545, 2012. Disponível em: <http://agbcampinas. com.br/bcg/index.php/boletim-campineiro/article/viewFile/86/2012v2n3_ Gottmann>. Acesso em: 10 nov. 2017.

HAESBAERT, R. Viver no limite: território e multi/transterritorialidade em tempos de in-segurança e contenção. 1. ed. Rio de Janeiro: Bertrand Brasil, 2014.

HEREDIA, B.; PALMEIRA, M.; LEITE, S. Sociedade e economia do agronegócio no Brasil. Revista Brasileira de Ciências Sociais, São Paulo, v. 25, n. 74, p. 159176, out. 2010.

LEITE, S. P.; MEDEIROS, L. S. Agronegócio. In: CALDART, R. S. et. al. (Org.). Dicionário da Educaçáo do Campo. 1. ed. Rio de Janeiro: Escola Politécnica de Saúde Joaquim Venâncio; São Paulo: Expressão Popular, 2012. 788 p. Verbete: Agronegócio, p. 81-87.

LOCKS, G. A; GRAUPE, M. E; PEREIRA, J. A. Educação do campo e direitos humanos: uma conquista, muitos desafios. Conjectura: Filos. Educ., Caxias do Sul, v. 20, n. especial, p. 131-154, 2015. 
MOLINA, M. C; FREITAS, H. C. A. Avanços e desafios na construção da educação do campo. Em Aberto, Brasília, DF, v. 24, n. 85, p. 17-31, abr. 2011. Disponível em: <http://emaberto.inep.gov.br>. Acesso em: 8 jul. 2014.

NASCIMENTO, C. G. Educaçáo do campo e políticas públicas para além do capital: hegemonias em disputas. Tese (Doutorado em Educação) - Faculdade de Educação, Universidade de Brasília, Brasília, DF, 2009.

RAFFESTIN, C. Por uma Geografia do poder. Tradução de Maria Cecília França. São Paulo: Ática, 1993.

RONDÔNIA. Relatório do Encontro Estadual de Educaçáo em Direitos Humanos. Comitê Estadual de Educação em Direitos Humanos de Rondônia. Porto Velho/RO -15 set. 2005. Disponível em: <http://www.dhnet.org.br/educar/ encontros_edh/a_pdf/ro_encontro_edh.pdf $>$. Acesso em: 24 mar. 2018.

SANTOS, B. de S; ARAÚJO, S; BAUMGARTEN, M. As Epistemologias do Sul num mundo fora do mapa. Sociologias, Porto Alegre, ano 18, n. 43, p. 14-23, set/dez 2016.

SANTOS, M. O dinheiro e o território. GEOgraphia, Rio de Janeiro, ano. 1, n. 1, p. 7-13, 1999. Disponível em: <http://www.geographia.uff.br/index.php/ geographia/article/viewFile/2/2>. Acesso em: 20 out. 2016.

SAQUET, M. A. As diferentes abordagens do território e a apreensão do movimento e da (i)materialidade. Geosul, Florianópolis, v. 22, n. 43, p. 55-76, jan./jun. 2007.

SILVA, B. G. A Marcha das Margaridas: resistências e permanências. Sociedade e Estado, Brasília, DF, v. 23, n. 2, p. 487-498, maio/ago. 2008.

SILVA JÚNIOR, A. F; BORGES NETTO, M. Por uma educação do campo: percursos históricos e possibilidades. Entrelaçando - Revista Eletrônica de Culturas e Educaçáo, Caderno temático: Cultura e Educação do Campo, Cruz das Almas, Ano 2, n. 3 p. 45-60, nov. 2011.

SILVA, M. Enera tem o desafio de criar um novo espaço de articulação entre os trabalhadores da educação, MST, 15 jul. 2015. Disponível em: <http://www.mst. org.br/2015/07/15/enera-tem-o-desafio-de-criar-um-novo-espaco-de-articulacaoentre-os-trabalhadores-da-educacao.html>. Acesso em: 08 jan. 2016.

SILVA, R. G. C. Amazônia globalizada: da fronteira agrícola ao território do agronegócio - o exemplo de Rondônia. Confins - Revista franco brasileira de Geografia, Paris, v. 23, p. 1-30, 2015. Disponível em: <http://confins.revues. org/9949>. Acesso em: 25 nov. 2016. 
SILVA, R. G. C. Da apropriação da terra ao domínio do território: as estratégias do agronegócio na Amazônia brasileira. International Journal of Development Research, v. 7, n. 12, p. 17699-17707, dez. 2017.

SILVA, R. G. C.; CONCEICAO, F. S. Agronegócio e campesinato na Amazônia brasileira: transformaçóes geográficas em duas regióes nos estados de Rondônia e Pará. GEOgraphia, Rio de Janeiro, v. 19, p. 54-72, 2017.

SOUZA, M. S.; MARCOCCIA, P. C. de P. Educaçáo do Campo, escolas, ruralidades e o projeto do PNE, Salvador, v. 20, p. 191-204, jul./dez. 2011.

SUAVE, M. P. O ensino da Geografia: uma perspectiva crítica para abordar o agrário no Estado de Rondônia. In: SIMPÓSIO INTERNACIONAL DE GEOGRAFIA AGRÁRIA, 8., SIMPÓSIO NACIONAL DE GEOGRAFIA AGRÁRIA (SINGA) 9., 2017, Curitiba. Anais... Curitiba: 2017. 